\title{
Le dilemme
}

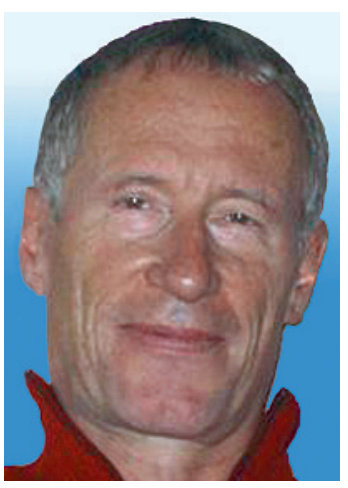

Erhard Taverna
1 Theillier P. Vocation du bureau médical. Bulletin de l'Association médical internationale. Numéro spécial. 1998. F-65108 Lourdes Cedex, bmedical@lourdes-france.com

2 Comte-Sponville A. L'esprit de l'athéisme. Introduction à une spiritualité sans Dieu. Paris: Editions Albin Michel; 2006.
Pour l'Association Médicale Internationale de Lourdes (AMIL), une guérison miraculeuse doit remplir deux conditions: elle doit se manifester hors des règles médicales habituelles, de manière extraordinaire et imprévue, et mener vers la foi la personne guérie et les témoins de la guérison. Cette définition s'appuie explicitement sur celle du Petit Robert: «Le miracle est un fait extraordinaire où l'on croit reconnaître une intervention divine bienveillante, auquel on confère une signification spirituelle.» Rappelons à ce propos Bernadette Soubirous, la fille d'un pauvre meunier, âgée de 14 ans, à laquelle une dame vêtue de blanc est apparue à plusieurs reprises alors qu'elle ramassait du bois au bord de la Gave, l'initiant aux Mystère du Chapelet. En 1862, l'église catholique suivit l'avis populaire et accepta l'événement comme une apparition de la Vierge. Depuis, plus de 5 millions de pèlerins se rendent chaque année à Lourdes, dont 70000 malades et leurs accompagnants hébergés dans 8 hôpitaux. Jusqu'à la première guerre mondiale, le nombre de guérisons «certaines, définitives et inexplicables» reconnues se montait à 1 sur 100, de 1914 à 1928, à 1 sur 700, puis jusqu'en 1947 à 1 sur 1600 . De 1947 jusqu'en 1990, on ne comptabilisa plus que 29 guérisons officielles. Le dilemme est évident: le point de vue scientifique s'accorde de plus en plus rarement avec le point de vue religieux et à ce rythme, il n'y aura bientôt plus de miracles. En effet, les critères d'exclusion deviennent de plus en plus stricts et la reconnaissance toujours plus compliquée. Une évaluation par étapes filtre les cas annoncés selon des critères détaillés: cela va de la «guérison attestée» à la «guérison accueillie», de la notion de guérison «vérifiée et confirmée» à celle plus stricte $\mathrm{d}^{\prime}$ «expertisée» pour aboutir à la «guérison proclamée-canonique». Ce parcours hiérarchique soumis à divers comités composés de médecins et de prêtres peut durer 10 à 15 ans. La difficulté fondamentale est énoncée clairement: «En réduisant la notion de miracle à des guérisons inexplicables, l'Eglise a, en fait, permis à la science médicale d'usurper sa propre compétence à interpréter les signes divins.» Grâce à cela, la primauté de l'église est restaurée. Elle est en effet la seule à pouvoir reconnaître et évaluer l'évidence de ces signes. Le miracle est réinterprété avec prudence et n'appartient qu'à celles et ceux qui croient en Dieu dans la tradition catholique, car «ces signes de Dieu ne sont signifiants que pour les croyants qui restent en lien avec le magistère épiscopal.» Ainsi, il est aisé d'énumérer les exclus: l'Islam, le New Age, les pratiques occultes et magiques. La science est au service de la théologie qui est seule à pouvoir déterminer les critères d'une guérison miraculeuse. La santé physique est une chose, le salut de l'âme en est une autre. Les médecins doivent certes continuer à effectuer un tri rigoureux, mais le critère déterminant est le miracle en tant qu'acte de grâce et marque divine qui renforce la foi: «L'arbre du miracle ne cache plus la forêt des guérisons.» [1] Conformément à la répartition des tâches prévues, la Commission médicale de Lourdes a désormais pour mission d'étudier l'évolution des maladies et d'exclure toute forme de simulation. Les compétences sont ainsi clairement attribuées et les miracles du seul ressort de l'église.

Que reste-t-il à ceux qui n'appartiennent pas à la masse des pèlerins se rendant à Lourdes? «Que puis-je savoir? Que dois-je faire? Que puis-je espérer?», se demandait Kant dans la Critique de la raison pure. Il est déjà suffisamment étonnant que le monde existe et magnifique que nous puissions penser. Le philosophe français André Comte-Sponville a trouvé des réponses pour ceux qui n'ont pas besoin de dogmes. Son livre «L'esprit de l'athéisme. Introduction à une spiritualité sans Dieu» [2] est un discours profond en 3 parties: Peut-on renoncer à la religion? Dieu existet-il? Quelle spiritualité pour les athées? Comte se réfère exclusivement à l'histoire et à la tradition judéo-chrétienne, qu'il résume avec intelligence, savoir et subtilité. Il décortique les signes divins traditionnels, évoque la tentation du nihilisme et la barbarie postmoderne, se confronte au mal et démontre objectivement, en toute simplicité et sans le moindre prosélytisme, comment vivre une spiritualité sans Dieu au quotidien. Selon lui, la laïcité est le plus précieux héritage des Lumières. Et comme il estime que ce bien est aujourd'hui compromis par la montee des fanatismes de tout bord, il souligne l'importance de la liberté de religion, mais aussi du droit à vivre sans religion.

Erhard Taverna 